\title{
“NOOR-2013" A BOLD SEEDED AND HIGH YIELDING CHICKPEA KABULI VARIETY DEVELOPED INDIGENOUSLY
}

\author{
M. Naveed ${ }^{1,2 *}$, M. Shafiq ${ }^{1}$, M. Nadeem ${ }^{3}$, A. U. Haq ${ }^{1}$ and M. A. Zahid ${ }^{1}$ \\ ${ }^{1}$ Pulses Research Institute, Ayub Agricultural Research Institute, Faisalabad, Pakistan \\ ${ }^{2}$ Plant Breeding Institute, The University of Sydney, Narrabri campus 2390, NSW, Australia \\ ${ }^{3}$ Cotton Research Station, Ayub Agricultural Research Institute, Faisalabad, Pakistan \\ *For correspondence: naveed1735@yahoo.com
}

\begin{abstract}
The evolution of new crop varieties with desirable traits is a continuous process. A crop variety becomes susceptible to various biotic and abiotic plant stresses with the passage of time, thus, necessitating replacement by genotypes possessing better productivity potential and inbuilt tolerance against different stresses. In this perspective, this article reports the progress of a new chickpea kabuli variety "Noor-2013" developed through conventional plant breeding techniques and possesses improved yield potential, extra bold seed size and ability to tolerate different diseases. In 199900, two local genotypes, K-96033 (female parent) and K-92029 (male parent) were crossed to create genetic variability for grain size by selecting high yielding recombinants with bold grains. For this purpose, from filial generation one $\left(\mathrm{F}_{1}\right)$ seed, an $\mathrm{F}_{2}$ population was raised and 299 single plant selections (SPS) were made which were advanced to subsequent generations $\left(F_{3}\right.$ to $\left.F_{5}\right)$ over the years in plant-to-row progenies using the pedigree method of plant selection. Only high yielding recombinants with bold grains were advanced to the next generations. Finally, a promising uniform line " $\mathrm{K}$ 60062" later named as "Noor-2013" with pedigree C.19/19/19/109/148/161/62 was selected from $F_{6}$ recombinants during 2005-06. Later, this line was evaluated for yield potential, and disease reaction during 2006-2013. On an average in different yield trials (station, adaptation and national), this strain produced $32.3 \%$ higher yield in comparison to check varieties/standards (Punjab-Noor, CM-2008, CM-2000 and Noor-91). In this process, the candidate variety "Noor-13" achieved a potential yield of $3282 \mathrm{~kg} \mathrm{ha}^{-1}$ in national uniform yield trials (NUYTs) during 2010-11 conducted at Arid Zone Research Institute (AZRI), Bhakkar, Punjab, Pakistan. The grains of this new variety is beige in colour, ramheaded with the 100-grain weight of $34 \mathrm{~g}$. Wider-canopy spread with semi-erect to semi-spread growth habit, bold grains, higher grain yield, resistance to fusarium oxysporum and moderately resistance to ascochyta rabiei are its salient characteristics. This article concludes that the art of conventional plant breeding still leads the modern era of biotechnology in crop varietal development with desirable traits.
\end{abstract}

Keywords: Chickpea kabuli, yield potential, bold seed, fusarium wilt, ascochyta blight.

https://doi.org/10.36899/JAPS.2020.4.0104

Published online April 25, 2020

\section{INTRODUCTION}

Chickpea, a cool-season and self-pollinated $(2 \mathrm{n}=2 \mathrm{x}=16)$ legume, belongs to genus Cicer that comprises one (1) cultivated and forty-three (43) wild species. It is grown in more than fifty $(>50)$ countries largely on arid to semi-arid tropics and occupies an important position among the food legumes worldwide. Its grains are a rich source of minerals, vitamins, essential amino acids and high-quality protein, which is twice in the amount as of cereals. Its natural ability to improve soil health and to reduce crop nitrogen demands by fixing atmospheric nitrogen $(\mathrm{N})$ through nodulation fits it well in sustainable agricultural production systems (Naveed $e t$ al., 2015a; Kaloki et al., 2019a).

Based on seed characteristics, chickpeas can be categorized into two types' viz., desi and kabuli. Desi types have darker but smaller seeds with rough seed coats, while, kabuli types have larger but lighter coloured seeds with smooth seed coats. Globally, it is now an established fact that lack of genetic diversity in cultivated species, arietinum, limit the scope of desired improvement essential for achieving sustainability in chickpea production. Restricted/limited distribution of Cicer reticulatum (a wild progenitor), loss of genetic variation associated with domestication (founder effect), and replacement of locally adapted landraces with genetically uniform modern varieties are the major reasons of the narrow genetic base of cultivated chickpea. These issues have also made it vulnerable to various biotic and abiotic stresses. Therefore, concentrated breeding efforts are required for developing and exploiting genetically diverse germplasm (Abbo et al., 2003).

Pakistan is an important player in world chickpea acreage ( 0.98 million hectares), production (330 thousand tonnes), and consumption (324 thousand 
tonnes). The Punjab province leads with a share of more than $90 \%$ in acreage and $80 \%$ in production (Anonymous, 2017-18). Chickpea desi which accounts for nearly $85 \%$ share in area, is predominantly cultivated in "Thal region" and depends on soil moisture received from pre-season rainfalls, however, chickpea kabuli which is mainly grown on rainfed areas of "Pothowar" and irrigated areas of "Bahawalnagar and Thal" contributes about $15 \%$ in area (Haq et al., 2002). In spite of ranking second in world chickpea acreage, the total production of Pakistan is low, unstable and well below the domestic requirements. Therefore, it has to import huge quantity, annually, from the Middle East, Australia and Canada to meet local consumption demands. The bold grains and attractive colour of imported chickpeas are the features, which makes them popular among the consumers.

In Pakistan, various biotic (fusarium wilt, ascochyta blight etc.) and abiotic (drought, heat, cold etc.) factors when emerging individually or in different combinations become lethal and affect chickpea production, adversely (Naveed et al., 2016a, Naveed et al., 2019). Wilt, a devastating disease of chickpea in Pakistan, can cause yield losses up to 12 million rupees, annually (Shah et al., 2009). It is most prevalent in the subcontinent, and adjoining countries like Burma, Iran and to some extent in Mexico, and Spain (Aslam et al., 2013a). Its casual organism, fusarium oxysporum, is a root pathogen and transmits through the soil. This pathogen completely blocks xylem vessels, thus, obstructs the food supply to above-ground plant parts (Singh et al., 2006). Chickpea blight, on the other hand, caused by ascochyta rabiei, develops mostly under moist and humid conditions and can cause yield losses up to 5070\% (Malik and Bashir, 1984). This disease appears only in epidemic form in years, and in countries, receiving higher rainfall during various developmental stages and sometimes may cause complete failure of the crop under severe attack (Bokhari et al., 2011).

Development of disease and other stress-tolerant cultivars is the most effective and least expensive way to deal with different yield losses (Shah et al., 2010; Sarwar et al., 2012; Naveed et al., 2015a; Khan et al., 2016; Naveed et al., 2016b,c; Devasirvatham and Tan, 2018). For this reason, the evolution of new genotypes and release as crop varieties is a continuous process and the ultimate objective of any crop-breeding program (Naveed et al., 2016a). The evolution of a new crop cultivar is not a straight-forward process, rather, it is a lengthy process extending up to more than 10 years depending upon the mode of pollination, breeding techniques, selection criterion and many other steps/formalities. These may include selection of parents from screening experiments, attempting different crosses, single plant selections and filial generation advancements, reaction to different stresses (biotic and abiotic), agronomic studies, evaluation for yield and its components, distinguishing uniformity stability (DUS) studies, presenting for spot examination, approval, registration and release for general cultivation by Provincial Seed Council. However, with the passage of time, a variety/genotype becomes vulnerable to many pathotypes resulting in low and unstable yields, thus, demanding replacement with the newer ones possessing inbuilt tolerance and better yield potential.

Local chickpea breeders have made substantial efforts in releasing varieties with improved yield potential and disease tolerance (Arshad et al., 2008; Shah et al., 2010; Shafiq et al., 2011; Aslam et al., 2013b). However, all chickpea varieties developed and released so far for general cultivation in Pakistan were medium-tobold seeded (up to $28 \mathrm{~g}$ weight of 100 seeds) and until now, no one succeeded in developing chickpea variety with bold grains that could compete with imported chickpeas. With this objective, the presently reported breeding efforts were initiated at Pulses Research Institute (PRI), Ayub Agric. Research Institute (AARI), Faisalabad, Pakistan.

\section{MATERIALS AND METHODS}

Based on yield potential, seed size and disease resistance, two strains (K-96033 \& K-92029) belonging to kabuli types of chickpea were selected as parents for the purpose of hybridization. Both the parents differ in growth habit, grain size, yield potential and wilt reaction. Entry K92029 being spreading in nature, bold seeded and wilt resistant used as a male parent while entry K-96033 erect in nature with better yield potential used as the female parent.

Hybridization $\left(\mathbf{F}_{\mathbf{0}}\right)$ : In order to create genetic variability, various crosses were attempted during 1999-00 at the experimental area of Pulses Research Institute (PRI), Faisalabad, Pakistan. In order to facilitate the activity of hybridization, both male and female parents were planted side by side in equal row lengths and by maintaining distances of $30 \mathrm{~cm} \mathrm{P-P} \mathrm{and} 60 \mathrm{~cm} \mathrm{R-R.} \mathrm{From} \mathrm{mid-}$ February to mid-March, immature, unopened flowers from female plants were emasculated manually using a forceps followed by pollination (Singh, 1987). The pollen collected from male parent plants were dusted immediately on female parent plants. This was done early in the morning between 9:00 am to 11:00 am to avoid any chance of selfing. Once the crossed flowers successfully developed into pods and attained physiological maturity, they were harvested, thrashed to obtain $\mathrm{F}_{0}$ seeds. Year by year developmental history of newly approved chickpea kabuli variety is revealed in Table-1.

Advancement of filial generations ( $F_{1}$ to $\left.F_{6}\right)$ : During cropping season of $2000-01, \mathrm{~F}_{0}$ seeds were field planted to raise phenotypically uniform but heterogeneous $F_{1}$ 
hybrid plants. The $\mathrm{F}_{0}$ seeds were sown inside row of parental lines in equal lengths of $4 \mathrm{~m}$ by using a dibbler and maintaining standard distances of $20 \mathrm{~cm}$ and $30 \mathrm{~cm}$ P$\mathrm{P}$, and R-R, respectively. The harvested $\mathrm{F}_{1}$ seeds from every single plant were bulked and used to raise the $F_{2}$ population during the next cropping season. Single plant selections (SPS) were made based on desirable characteristics, visually, starting from $F_{2}$ generation to subsequent ones leading up to $\mathrm{F}_{5}$ generation. Bulk and pedigree methods of plant selections were practised during the reported breeding-phase. From $\mathrm{F}_{6}$ generation, only uniform, true to type pure lines were selected and bulked for further testing in different yield (station, adaptation and national trials), and supporting trials.

General experimental details: During land preparation, one bag of DAP fertilizer at the rate of per acre was mixed in the soil. All practices (agronomic and cultural) like weeding/hoeing, irrigation, and insecticidal spray except entomological trials were kept the same for all the experimental genotypes. The design used was a randomized complete block (RCB) with three replications for all yield, entomological and bacteriological trials. The standard R-R and P-P distances maintained were $30 \mathrm{~cm}$ and $15 \mathrm{~cm}$, respectively. In all the trials, two seeds per hole were placed in order to maintain per plot plant population, which were thinned to one vigorous seedling after 20-25 days of germination.

Yield trials: A plot size of $4 \times 1.2 \mathrm{~m}^{2}$ was kept uniform for all station (preliminary, advanced) and adaptation (micro, co-operative) yield trials in comparison to $4 \times 1.8$ $\mathrm{m}^{2}$ plot size of national uniform yield trials (NUYTs). Each trial comprised at least one to two checks for evaluating the performance of test entries. Measurements recorded were germination \%age, days to $50 \%$ flowering (DTF), days to $90 \%$ maturity (DTM), pods per plant, 100 -seed weight $(\mathrm{g})$, and yield per plot $(\mathrm{g})$. The yield in all the trials was converted into $\mathrm{kg} \mathrm{ha}^{-1}$ for reporting in an official framework.

Pathological studies: For conducting screening experiments pertaining to fusarium wilt and ascochyta blight, all the genotypes were laid-out in an augmented design replicated twice with a plot size of $0.3 \mathrm{~m}^{2}$ for each entry.

Experiments to assess the response of test entries to fusarium wilt were conducted on a natural wiltsick plot maintained by continuously building inoculum of relevant pathotypes. Every two-test entries accompanied by a susceptible check named "AUG-424" on both sides, were planted with a view to build-up the inoculum pressure. All the susceptible lines exhibited hundred-per cent wilt attack, which revealed the highest level of field infestation. The first recording of wilt frequency was done 30 days after sowing followed by 10 days interval between recordings till the crop maturity.
The reaction of each genotype to fusarium wilt in terms of resistance and susceptibility was determined by following disease-rating scale (DRS) of Iqbal et al., (1996).

For ascochyta blight studies, a plastic tunnel with a sprinkler system was used for creating more than $90 \%$ artificial mist, conducive for the appearance of ascochyta disease. Punjab-1 being used as a spreader/check was planted after every two test-entries in order to record the intensity/severity of the disease. Plants were inoculated by spraying at 8-10 leaf stage, usually during the first week of February, however, scoring was done after about fourteen days of inoculation on 0 to 9 DRS (Shah et al., 2005).

Entomological studies: Gram pod borer is the only insect pest that can cause yield losses up to an economic threshold level. Therefore, these studies were conducted for assessing the percentage of pod borer infestation. For estimating infestation \%age, total pods and infested pods per plant were counted and the percentage was worked out.

Bacteriological studies: Field trials were conducted for the assessment of responses of both candidate and check varieties under two treatments of un-inoculation and rhizobial inoculation. Measurements were recorded on nodules per plant and grain yield per plant.

\section{RESULTS}

Among the various cross combinations attempted during 1999-00, cross number (C. \#) nineteen (19) comprising local lines, 96033 and K-92029 revealed maximum $\mathrm{F}_{0}$ seed settings i.e. 13 seeds. During the next cropping season (2000-01), these seeds were fieldplanted to raise $F_{1}$ generation. Seeds of parental lines were also sown to compare the plant phenotypes of parents and hybrids $\left(\mathrm{F}_{1}\right)$. Out of thirteen $\mathrm{F}_{0}$ seeds, only nine germinated, developed into seedlings and whole plants. On attaining physiological maturity, seeds from nine plants were harvested, thrashed, bulked and labelled as $F_{1}$ seeds. Next year i.e. 2001-02, $F_{2}$ generation was raised from $F_{1}$ seeds by allowing them to self-pollinate. About 299 SPS were made from $\mathrm{F}_{2}$ plant population. These plant selections were done at $90 \%$ pod setting based on plant vigour and pod size. Once matured, each of these plants was harvested, thrashed and their seeds kept separately. Based on seed size and yield per plant, 153 out of 299 single plants were selected for further evaluation in subsequent generations. During cropping season of 2002-03, plant rows in the $F_{3}$ generation were raised by planting $153 \mathrm{~F}_{2}$ SPS on the wilt-sick bed. Most of these plant-rows were destroyed by the attack of fusarium wilt, however, among the survived ones, progeny no. 109 revealed wilt resistance, higher and bolder pods, hence greater yield per plant. After 
harvesting and thrashing, the seeds obtained from this progeny were bulked. During 2003-04, this bulked seed used to sow 161 families of plant-rows under normal soil conditions in the $\mathrm{F}_{4}$ generation. Regular field visits revealed progeny no. 148 with plants of different growth habits viz., erect, semi-erect, semi-spread, spread but some with medium and others with bold grains. All these SPS were harvested and thrashed separately. However, SPS with bold grains were separated and used to sow 171 plant-row families in $\mathrm{F}_{5}$ generation during the cropping season of 2004-05. Regular field visits revealed progeny no. 161 largely uniform. The plants were semi-erect to semi-spread in growth habit and with bold pods/seed size. Seeds harvested from this progeny advanced to $\mathrm{F}_{6}$ generation to plant seventy-nine (79) progeny-rows during the year of 2005-06. Regular field visits were conducted and observations were recorded. It was noticed that the plant types in progeny no. 62 were semi-erect to semi-spread, true-to-type/uniform in appearance, bear greater no. of pods with bold grains. These plants were harvested, thrashed and bulked so that sufficient quantity of seed is available for further testing. In this way, entry K-60062 was evolved and its pedigree can be written as C.19/19/19/109/148/161/62.

Advance line K-60062 was then evaluated for yield potential in a series of trials conducted at different locations and over the years. In these trials, the performance of $\mathrm{K}$ 60062 was very good. Yield performance of K-60062 along with checks is presented in Table-2. In station (preliminary and advance) yield trials, candidate line K-60062 produced grain yield in the range of 1129 to $1771 \mathrm{~kg} \mathrm{ha}^{-1}$. This is well over the yield performance of checks, Noor -91 (932 to 1528 $\mathrm{kg} \mathrm{ha}^{-1}$ ) and CM-2000 (590 kg ha-1 to $1109 \mathrm{~kg} \mathrm{ha}^{-1}$ ). The average yield of $1464 \mathrm{~kg} \mathrm{ha}^{-1}$ of K-60062 in station yield trials was much higher than the average of $1045 \mathrm{~kg} \mathrm{ha}^{-1}$ of both check varieties. Table- 3 revealed the performance of the candidate and check varieties in adaptation (micro and co-operative) yield trials. In these trials, K-60062 produced grain yield in the range of $649 \mathrm{~kg} \mathrm{ha}^{-1}$ to $2614 \mathrm{~kg} \mathrm{ha}^{-1}$ and outperformed checks, Noor-91 (521 to $2270 \mathrm{~kg} \mathrm{ha}^{-1}$ ) and CM-2008 (469 to $2330 \mathrm{~kg} \mathrm{ha}^{-1}$ ). The average yield of 1450 $\mathrm{kg} \mathrm{ha}^{-1}$ of K-60062 was six mounds higher than the average yield $\left(1210 \mathrm{~kg} \mathrm{ha}^{-1}\right)$ of both the checks. Yield performance of K-60062 in national uniform yield trials (NUYTs) is given in Table-3. Similar to station and adaptation yield trials, the performance of candidate variety in NUYTs was also better than Noor-91 and Punjab-Noor, the check varieties. During 2010-11 NUYTs, strain K-60062 achieved a yield potential of $3282 \mathrm{~kg} \mathrm{ha}^{-1}$ at AZRI, Bhakkar, Punjab, Pakistan. Average of both years NUYTs revealed a yield of $1360 \mathrm{~kg} \mathrm{ha}^{-1}$ in comparison to the average yield of $1166 \mathrm{~kg}$ $\mathrm{ha}^{-1}$ of Noor-91 and Punjab-Noor.

The response of candidate variety and standards to different irrigation levels is presented in Table-5. For three irrigation levels i.e. zero, one and two, agronomic and cultural practices including P-P and R-R distances, fertilizer applications were kept the same. Under rain- fed/zero irrigation, the performance of candidate line K60062 was at par to check cultivars, CM-2008 and Punjab-Noor. However, candidate variety K-60062 responded well to irrigation level one by producing a yield of $1686 \mathrm{~kg} \mathrm{ha}^{-1}$ in comparison to $1504 \mathrm{~kg} \mathrm{ha}^{-1}$ of CM-2008 and $1590 \mathrm{~kg} \mathrm{ha}^{-1}$ of Punjab-Noor. Likewise, K60062 even responded better to irrigation level two and yielded $2134 \mathrm{~kg} \mathrm{ha}^{-1}$ in contrast to $1911 \mathrm{~kg} \mathrm{ha}^{-1}$ of CM2008 and $2101 \mathrm{~kg} \mathrm{ha}^{-1}$ of Punjab-Noor. Average of all three irrigation levels revealed a yield of $1695 \mathrm{~kg} \mathrm{ha}^{-1}$ of $\mathrm{K}-60062$ in comparison to $1606 \mathrm{~kg} \mathrm{ha}^{-1}$ of both standard cultivars.

The reaction of K-60062 to ascochyta blight and fusarium wilt is presented in Table-6. These studies were conducted during 2011-13 under a tunnel and wilt-sick bed, respectively. For chickpea blight, both candidate and standard cultivars were placed under scale 5, therefore, declared as moderately resistant (MR). However, against chickpea wilt, K-60062 was placed under scale 3 as resistant $(\mathrm{R})$ while the check variety Punjab-Noor under scale 5 as MR. This information on disease reaction and performance in yield trials confirmed the scope of cultivation of this candidate line on a range of soil types and environments conducive for the development of different diseases.

Entomological studies regarding the infestation of gram pod borer on K-60062 and standard cultivars is presented in Table-7. Data regarding pod infestation \%age revealed lesser infestation on K-60062 in comparison to Punjab-Noor. However, these differences were non-significant statistically.

The response of candidate and check varieties to rhizobial inoculation (RI) is given in Table-8. The data revealed that the nodules number and yield increased under inoculation in comparison to un-inoculation. Under inoculation conditions, K-60062 produced 16-18 nodules per plant and yielded $1432 \mathrm{~kg} \mathrm{ha}^{-1}$ to $1769 \mathrm{~kg} \mathrm{ha}^{-1}$ while PunjabNoor produced 14-16 nodules per plant and yielded $1374 \mathrm{~kg}$ $\mathrm{ha}^{-1}$ to $1463 \mathrm{~kg} \mathrm{ha}^{-1}$. Similarly, the response of K-60062 under un-inoculated conditions was better than check cultivar. It produced 10-11 nodules per plant and yielded $1109 \mathrm{~kg} \mathrm{ha}^{-1}$ to $1490 \mathrm{~kg} \mathrm{ha}^{-1}$ while Punjab-Noor produced 9. 10 nodules per plant and yielded in the range of $1090 \mathrm{~kg} \mathrm{ha}^{-1}$ to $1244 \mathrm{~kg} \mathrm{ha}^{-1}$.

Various qualitative and quantitative characteristics of K-60062 in comparison to Punjab-Noor are presented in Table-10. The candidate line revealed differences with the check, Punjab-Noor in stem characteristics like plant height, growth habit, canopy spread, primary and secondary branches per plant. Differences in leaf traits such as colour, leaflets per leaf and leaf hairiness were also recorded. Similarly, distinctiveness was also noticed for reproductive traits such as phenology (days to flowering and maturity), pods (size and number), seeds (colour and 100-seed weight), yield potential and disease reaction. 
Table-1. Different stages of selection of K-60062 as "Noor-2013".

\begin{tabular}{lll}
\hline Year & Filial generation/trial & Operation \\
\hline $1999-00$ & Hybridization & F seed harvested \\
$2000-01$ & $\mathrm{~F}_{1}$ & $\mathrm{~F}_{1}$ seed harvested \\
$2001-02$ & $\mathrm{~F}_{2}$ & Single plant selection \\
$2002-03$ & $\mathrm{~F}_{3}$ & Plant to row progenies \\
$2003-04$ & $\mathrm{~F}_{4}$ & - do- \\
$2004-05$ & $\mathrm{~F}_{5}$ & - do- \\
$2005-06$ & $\mathrm{~F}_{6}$ & Uniform line selected and bulked \\
$2006-07$ & Preliminary Yield Trial & Yield data were recorded \\
$2007-08$ & Advanced Yield Trial & -do- \\
$2008-09$ & Micro Yield Trial & -do- \\
$2009-10$ & Co-operative Yield Trial & -do- \\
$2009-10$ & National Uniform Yield Trial & -do- \\
$2010-11$ & National Uniform Yield Trial & -do- \\
$2011-12$ & Agronomic Studies & Response to different irrigation levels \\
$2011-13$ & Pathological Studies & Reaction to fusarium wilt \& ascochyta blight \\
$2012-13$ & Entomological Studies & Infestation of gram pod borer \\
$2011-13$ & Bacteriological Studies & Response to rhizobial inoculation \\
$2013-17$ & Seed Production (BNS) & Maintenance and supply of breeder nuclear seed to seed \\
& & companies and farming community \\
\hline
\end{tabular}

Table-2. Performance of K-60062 as "Noor-2013" in station yield trials (SYT).

\begin{tabular}{|c|c|c|c|c|c|}
\hline \multirow[t]{3}{*}{ Year } & \multirow[t]{2}{*}{ Name of Trial / Locations } & \multicolumn{3}{|c|}{ Yield (kg/ha) } & \multirow{2}{*}{ +/- Over checks (\%) } \\
\hline & & Check (s) & & K-60062 & \\
\hline & \multicolumn{4}{|c|}{ Preliminary Yield Trial (PYT) } & \\
\hline \multirow{4}{*}{$2006-07$} & AARI Faisalabad & CM-2000 & 1109 & \multirow{4}{*}{1129} & 1.8 \\
\hline & AARI, Faisalabad & Noor-91 & 932 & & 21.1 \\
\hline & Average $+/$ - over checks $(\%$, & & & & 11.5 \\
\hline & Advanced Yield Trials (A) & & & & \\
\hline \multirow{6}{*}{ 2007-08 } & & CM-2000 & 1056 & \multirow{2}{*}{1493} & 41.4 \\
\hline & AARI, Faisalabad & Noor-91 & 1056 & & 41.4 \\
\hline & \multirow{2}{*}{ GBRSS, Kallurkot } & CM-2000 & 590 & \multirow{2}{*}{1771} & 200.2 \\
\hline & & Noor-91 & 1528 & & 15.9 \\
\hline & Average $+/$ over checks $(\%$ & & & & 74.7 \\
\hline & \multicolumn{2}{|l|}{$\begin{array}{l}\text { Average }+/ \text { - over checks (\%) } \\
\text { Overall average in } \boldsymbol{S Y T}\end{array}$} & 1045 & 1464 & 43.1 \\
\hline
\end{tabular}

Table-3. Performance of K-60062 as "Noor-2013" in adaptation yield trials (AYT).

\begin{tabular}{|c|c|c|c|c|c|}
\hline \multirow[t]{2}{*}{ Year } & \multirow[t]{2}{*}{ Name of Trial / Locations } & \multicolumn{3}{|c|}{ Yield (kg/ha) } & \multirow{2}{*}{ +/- Over checks $(\%)$} \\
\hline & & Check (s) & & K-60062 & \\
\hline \multirow[t]{9}{*}{ 2008-09 } & \multicolumn{5}{|l|}{ Micro Yield Trials (MYT) } \\
\hline & \multirow{2}{*}{ AARI, Faisalabad } & Noor-91 & 1794 & \multirow{2}{*}{2179} & 21.5 \\
\hline & & CM-2008 & 2069 & & 5.3 \\
\hline & \multirow{2}{*}{ GBRSS, Kallurkot } & Noor-91 & 2270 & \multirow{2}{*}{2614} & 15.2 \\
\hline & & CM-2008 & 2330 & & 12.2 \\
\hline & \multirow{2}{*}{ PRSS, Sahowali } & Noor-91 & 817 & \multirow{2}{*}{854} & 4.5 \\
\hline & & CM-2008 & 469 & & 82.1 \\
\hline & \multirow{2}{*}{\multicolumn{4}{|c|}{$\begin{array}{l}\text { Average }+/ \text { - over checks }(\%) \\
\text { Co-operative Yield Trials (CYT) }\end{array}$}} & 23.5 \\
\hline & & & & & \\
\hline \multirow{3}{*}{$2009-10$} & A DI Г⿸广 & Noor-91 & 567 & \multirow{2}{*}{649} & 14.5 \\
\hline & AARI, Falsalabad & CM-2008 & 549 & & 18.2 \\
\hline & NIAB, Faisalabad & Noor-91 & 1035 & 1533 & 48.1 \\
\hline
\end{tabular}




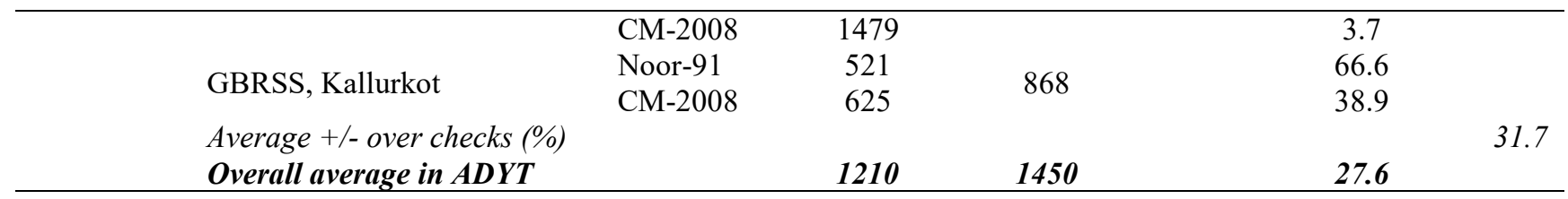

Table-4. Performance of K-60062 as "Noor-2013" in national uniform yield trials (NUYTs).

\begin{tabular}{|c|c|c|c|c|c|}
\hline \multirow[t]{2}{*}{ Year } & \multirow{2}{*}{ Locations } & \multicolumn{3}{|c|}{ Yield (kg/ha) } & \multirow{2}{*}{ +/- Over checks $(\%)$} \\
\hline & & Check (s) & & K-60062 & \\
\hline \multirow{10}{*}{$2009-10$} & BARI, Chakwal & \multirow{10}{*}{ Noor-91 } & 1708 & 2097 & 22.8 \\
\hline & NIAB, Faisalabad & & 1184 & 1599 & 35.1 \\
\hline & ARS, Karak & & 231 & 301 & 30.3 \\
\hline & AZRI, DIK & & 1694 & 1942 & 14.6 \\
\hline & BARS, Sakrand & & 950 & 794 & -16.4 \\
\hline & GBRSS, Kallurkot & & 810 & 1134 & 40.0 \\
\hline & BARS, Fatehjang & & 195 & 220 & 12.8 \\
\hline & AZRI, Bhakkar & & 127 & 338 & 166.1 \\
\hline & AARI, Faisalabad & & 472 & 458 & -3.0 \\
\hline & Average +/- over check (\%) & & & & 33.6 \\
\hline \multirow{8}{*}{$2010-11$} & NARC, Islamabad & \multirow{8}{*}{ Punjab- Noor } & 3171 & 2100 & -33.8 \\
\hline & BARI, Chakwal & & 1701 & 1840 & 8.2 \\
\hline & AZRI, Bhakkar & & 1859 & 3282 & 76.5 \\
\hline & NIAB, Faisalabad & & 1460 & 2092 & 43.3 \\
\hline & AARI, Faisalabad & & 1120 & 1576 & 40.7 \\
\hline & ARI, Sariab, Quetta & & 806 & 630 & -21.8 \\
\hline & Average +/- over check (\%) & & & & 18.9 \\
\hline & Overall average in $N U Y T$ & & 1166 & 1360 & 26.3 \\
\hline
\end{tabular}

Table-5. The response of K-60062 as "Noor-2013" to different irrigation levels.

\begin{tabular}{llccc}
\hline \multirow{2}{*}{ Irrigation level } & \multicolumn{2}{c}{ Yield (kg/ha) } & K-60062 & +/- Over check (\%) \\
\cline { 2 - 4 } & Checks & & 1265 & 0.71 \\
\multirow{2}{*}{ Zero } & CM-2008 & 1256 & & -0.55 \\
& Punjab-Noor & 1272 & & 10.8 \\
One & CM-2008 & 1504 & 1686 & 5.7 \\
\multirow{2}{*}{ Two } & Punjab-Noor & 1590 & & 10.5 \\
& CM-2008 & 1911 & 2134 & 1.6 \\
& Punjab-Noor & 2101 & $\mathbf{1 6 9 5}$ & $\mathbf{4 . 8}$ \\
\hline
\end{tabular}

Table-6. The reaction of K-60062 as "Noor-2013" to fusarium wilt and ascochyta blight.

\begin{tabular}{cllcll}
\hline \multicolumn{2}{c}{ Fusarium wilt } & \multicolumn{2}{c}{ Ascochyta blight } \\
\hline Grade & Reaction & Genotypes & Grade & Reaction & Genotypes \\
$\mathbf{1}$ & Highly Resistant & - & $\mathbf{0}$ & Immune & - \\
$\mathbf{3}$ & Resistant & K-60062 & $\mathbf{1}$ & Highly Resistant & - \\
$\mathbf{5}$ & Moderately & Punjab-Noor & $\mathbf{3}$ & Resistant & - \\
& Resistant & (check) & & & \\
$\mathbf{7}$ & Susceptible & - & $\mathbf{5}$ & Moderately & K-60062 \\
& & & & Resistant & Punjab-Noor (check) \\
$\mathbf{9}$ & Highly & - & $\mathbf{7}$ & Susceptible & - \\
& Susceptible & & $\mathbf{9}$ & Highly & - \\
& & & Susceptible & \\
\hline
\end{tabular}


Table-7. The infestation of gram pod borer on K-60062 as "Noor-2013".

\begin{tabular}{lcccc}
\hline Entries & No. of pods studied & Infested pods & \%age infested & Yield (kg/ha) \\
\hline K-60062 & 82 & 6 & $7.1 \mathrm{a}$ & $1498 \mathrm{a}$ \\
Punjab-Noor (check) & 84 & 6 & $7.3 \mathrm{a}$ & $1244 \mathrm{~b}$ \\
\hline
\end{tabular}

Table-8. The response of K-60062 as "Noor-2013" to rhizobial inoculation.

\begin{tabular}{lcccccc}
\hline & & \multicolumn{2}{c}{ 2011-12 } & \multicolumn{2}{c}{ 2012-13 } & Average \\
\cline { 3 - 6 } \multicolumn{1}{c}{ Treatment } & Trait & Punjab-Noor & K-60062 & Punjab-Noor & K-60062 & Aver \\
\hline Un-inoculation & No. of & 9 & 11 & 10 & 10 & $\mathbf{1 0}$ \\
Inoculation & Nodules & 16 & 18 & 14 & 16 & $\mathbf{1 6}$ \\
Un-inoculation & Yield & 1244 & 1490 & 1090 & 1109 & $\mathbf{1 2 3 3}$ \\
Inoculation & $\mathrm{kg} /$ ha & 1463 & 1769 & 1374 & 1432 & $\mathbf{1 5 1 0}$ \\
& + +- Yield (\%) & $\mathbf{1 7 . 6}$ & $\mathbf{1 8 . 7}$ & $\mathbf{2 6 . 1}$ & $\mathbf{2 9 . 1}$ & $\mathbf{2 2 . 9}$ \\
\hline
\end{tabular}

Table-9. Production of basic nuclear seed (BNS) of Noor-2013.

\begin{tabular}{lcccc}
\hline Year & $\mathbf{2 0 1 3 - 1 4}$ & $\mathbf{2 0 1 4 - 1 5}$ & $\mathbf{2 0 1 5 - 1 6}$ & $\mathbf{2 0 1 6 - 1 7}$ \\
\hline Quantity $(\mathrm{kg})$ & 695 & 940 & 675 & 830 \\
\hline
\end{tabular}

Table-10. Agronomical, morphological and qualitative plant traits of K-60062 as "Noor-2013" in contrast to the check, Punjab-Noor (Av. five years 2006-11).

\begin{tabular}{llll}
\hline & Traits & K-60062 & Punjab-Noor \\
\hline a & Stem & $60-65 \mathrm{~cm}$ & \\
1 & Plant height & Semi erect to Semi-spread & $60 \mathrm{~cm}$ \\
2 & Growth habit & Wide & Semi erect \\
3 & Canopy spread & Light green & Medium \\
4 & Stem colour & $7-11$ & Light green \\
5 & Primary branches & $8-15$ & $6-10$ \\
6 & Secondary branches & & $8-12$ \\
b & Leaf & Green & \\
1 & Leaf colour & $15-17$ & Waxy / light green \\
2 & Leaflets per leaf & Large & 15 \\
3 & Leaflets size & Medium & Large \\
4 & Leaf hairiness & $110-115$ & Absent \\
5 & Days to 90\% flowering & & $115-120$ \\
c & Pods & Large & \\
1 & Pod size & Absent & Large \\
2 & Shattering & $40-70$ & Absent \\
3 & Pods per plant & $1-2$ & $45-50$ \\
4 & Seeds per pod & $155-160$ & $1-2$ \\
5 & Days to maturity & & $165-170$ \\
d & Seeds & Ram's head & \\
1 & Seed shape & Beige & Ram's head \\
2 & Seed colour & 34 gm & Beige \\
3 & 100 seed weight & & 25 gm \\
e & Yield (kg ha ${ }^{-1}$ & $3282($ AZRI, Bhakkar) & \\
1 & Yield potential (NUYT) & 1360 & 3063 (AARI, Fsd) \\
2 & Average yield (NUYT) & All Punjab & 1319 \\
& Adaptive areas & & All Punjab \\
\hline
\end{tabular}




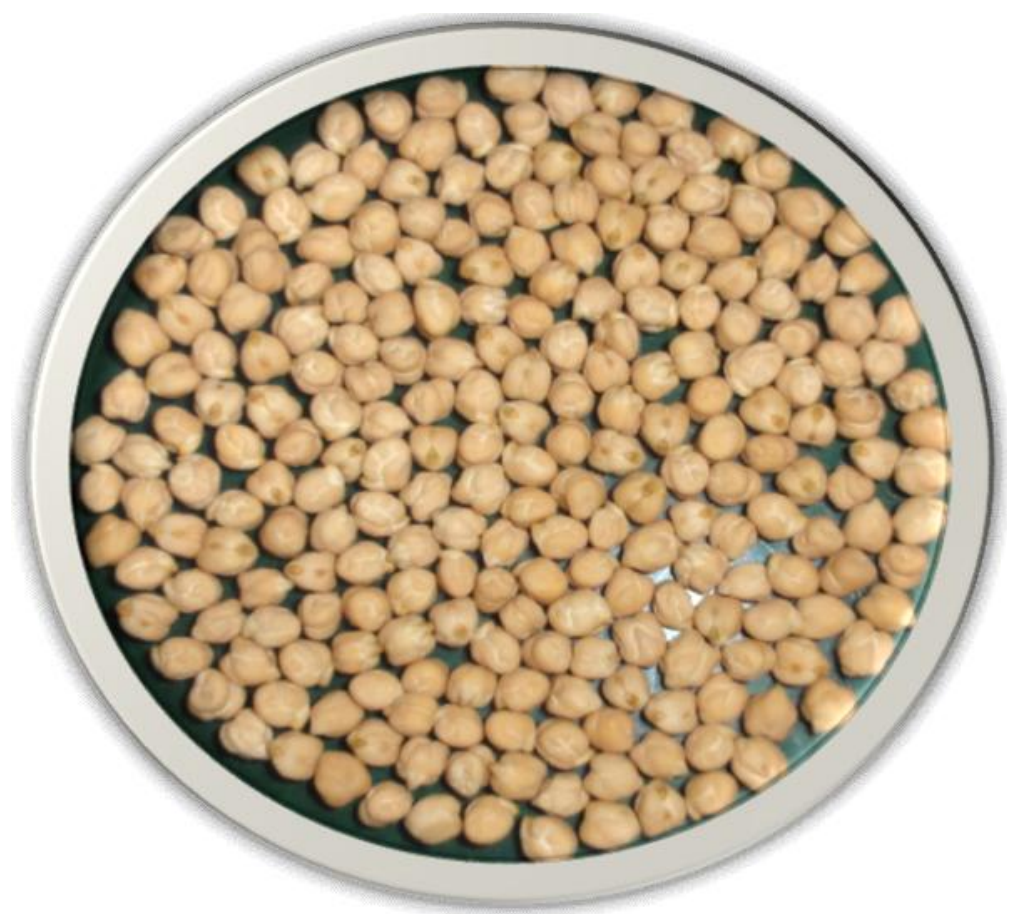

Figure-1. The grains of Noor-2013

\section{DISCUSSION}

The progress made during the $20^{\text {th }}$ century in the field of agriculture especially plant breeding and in developing new crop varieties with desirable characteristics is exceptional. The art of spotting distinctive and desirable traits and incorporating them into new or genotypes of interest is the main feature of conventional/traditional plant breeding (Maqbool et al., 2017). Since its practice dating back to human civilization, the contributions made over the years by this aspect of plant breeding towards sustainable agricultural production systems are over-whelming (Poehlman et al., 1995; Kaloki et al., 2019b). For instance, several chickpea cultivars (NIFA-88, Noor-91, Bittal-98, CM-98, CM-2000, Punjab-2000, Thal-2006, Punjab-2008, CM2008; Punjab-Noor, and Bhakkar-2011) in Pakistan and India (JGK-1 and PBG-2) were developed using this system (Hassan and Khan, 1991; Ali, 1999; Haq et al., 1999, 2002; Ali et al., 2004; Gaur et al., 2004; Sandhu et al., 2004; Shah et al., 2010; Shafiq et al., 2011; Aslam et al., 2013b). The latest chickpea kabuli variety, Noor2013, developed through this technique performed exceptionally well and consistently out-yielded checks during its evaluation phase. On average, Noor-2013 surpassed respective checks by $43.1 \%$ higher yield in station yield trials, with $11.5 \%$ in PYT and $74.7 \%$ in AYT. In adaptation or multi-location yield trials, the candidate line produced $23.5 \%$ higher yield in MYT and $31.7 \%$ in CYT. During both years of national testing, this strain produced $33.6 \%$ higher yield in $2009-10$ and $18.9 \%$ in 2010-11 over the checks, suggesting its adaptation and yield potential over a range of environmental conditions (Yadav et al., 2010). Furthermore, a candidate variety has to out-perform competing checks consistently for its approval and the results of Noor-2013 are in accordance to previously approved chickpea varieties (Shafiq et al., 2011; Aslam et al., 2013b).

Among the various agro-morphological traits of Noor-2013, its plant height ranged $60-65 \mathrm{~cm}$ with light green stem colour and spreading type (semi-erect to semispread) growth habit. It has a wider canopy with 7-11 primary branches and 8-15 secondary branches. It has large leaflets with 15-17 greenish leaflets per leaf and medium pubescence (hairiness). It takes 110-115 days for 90\% flowering and 155-160 days for physiological maturity. It has 40-70 pods per plant, with 1-2 seeds per pod. Pods are larger while shattering is absent. Its seeds are ram-headed, beige in colour with a 100 -seed weight of $34 \mathrm{~g}$ (Figure-1). The most important genetic improvement in this strain over previously approved chickpea cultivars is bold-seeded grain, inbuilt resistance (R) against fusarium wilt and moderate resistance (MR) against ascochyta blight. The bold-seeded trait is considered very important in ultimate crop productions and consumer preferences (Hassan and Khan, 1991; Waldia et al., 1996; Ali et al., 1999; Mehla et al., 2000; Sandhu et al., 2004; Shah et al., 2010; Naveed et al., 2015a). Noor-2013 revealed adaptation throughout Punjab, Pakistan with a yield potential of $3282 \mathrm{~kg} \mathrm{ha}^{-1}$ and an average yield of $1360 \mathrm{~kg} \mathrm{ha}^{-1}$. Regarding yield performance at the national level, this strain was among 
the top positions in NUYTs conducted during 2009-10 and 2010-11. Regarding ideotype of Noor-2013, it is ideal for cultivation in rain-fed and irrigated areas and for mechanical harvesting.

The ultimate crop production depends upon a number of factors, and seeding at the optimum time is one of them (Naveed et al., 2015b). For Noor-2013, data revealed that sowing during last-week of October to midNovember along with an application of nitrogen $(\mathrm{N})$ fertilizer@25-50 kg ha ${ }^{-1}$ and phosphorus (P) fertilizer@ $60-90 \mathrm{~kg} \mathrm{ha}^{-1}$ at the time of land preparation is best for achieving maximum production. Furthermore, seeding at a depth of 15 to $20 \mathrm{~cm}$ is recommended for good germination under water-deficit conditions, however, for a healthier crop, a distance of $15 \mathrm{~cm} \mathrm{P-P} \mathrm{and} 30 \mathrm{~cm}$ R-R should be maintained.

As far as genetic purity is concerned, Noor-2013 is regularly maintained at Pulses Research Institute (PRI), Faisalabad and its Substation (Gram Breeding Research Substation) at Kallurkot, Bhakkar, Pakistan. Since 2013 to 2017 , breeder nuclear seed (BNS) was supplied to chickpea growers and different seed producing agencies/companies for its better and effective adoption (Table-9). The Punjab Seed Council (PSC), Lahore approved this new strain "K-60062" under label "Noor2013" for commercial cultivation throughout Punjab, Pakistan.

Conclusions: Noor-2013 is a high yielding, bold seeded chickpea kabuli variety with inbuilt tolerance against major diseases of chickpea (fusarium wilt and ascochyta blight). This variety proved its worth consistently in station, adaptation and national yield trials and outyielded check varieties significantly. It is expected that Noor-2013 due to its desirable features will gain popularity among the farming community. Adoption of this variety in terms of seed multiplication and cultivation at farmer's field will surely contribute to sustaining, stabilizing and improving domestic chickpea production and in reducing ever-increasing chickpea import bill of Pakistan.

Acknowledgement: The facilitation and support provided by Punjab Agriculture Department and its allied directorates at Faisalabad (Agronomy, Plant Pathology \& Entomology) and outstations (AZRI, Bhakkar, BARI, Chakwal \& RARI, Bahawalpur), NIAB, Faisalabad, NARC Islamabad and FSC\&RD, Islamabad is greatly appreciated in evaluating this strain and making it worth approval.

\section{REFERENCES}

Abbo, S., J. Berger, and N.C. Turner (2003). Viewpoint: Evolution of cultivated chickpea: four bottlenecks limit diversity and constrain adaptation. Funct. Plant Biol., 30: 1081-1087
Ali, A. (1999). Bittal 98 (A-16), an improved form of the most predominant desi chickpea variety C-44. Int. Chickpea Pigeonpea Newsl. 6: 8-9

Ali, A., M. Ali, and M. Afzal (2004). Punjab 2000: A new large-seeded desi chickpea variety for Punjab province of Pakistan. Int. Chickpea Pigeonpea Newsl.11: 20-22

Anonymous (2017-18). Bureau of Statistics, Govt. of Pakistan, Islamabad.

Arshad, M., M. Aslam, and M. Sharif (2008). Performance of "Thal 2006" a high yielding and disease resistant variety of chickpea. J. Agric. Res., 46: 117-124

Aslam, M., M.A. Maqbool, S. Akhtar, and W. Faisal (2013a). Estimation of genetic variability and association among different physiological traits related to biotic stress (Fusarium oxysporum L.) in chickpea. J. Anim. Plant Sci., 23: 1679-1685

Aslam, M., N. Hussain, K. Hussain, and M. Sharif (2013b). Bhakkar-2011, a wilt resistant and high yielding chickpea variety. J. Agric. Res., 51: 247-254

Bokhari, A.A., M. Ashraf, A. Rehman, A. Ahmad, and M. Iqbal (2011). Screening of chickpea germplasm against Ascocyta blight. Pakistan J. Phytopathol., 23: 05-08

Devasirvatham, V., and D.Y.K. Tan (2018). Impact of high temperature and drought stresses on chickpea production. Agronomy, 8: 145

Gaur, P.M., V.K. Gour, A. Babber, O. Gupta1, J. Kumar, and B.V. Rao (2004). JGK 1: A new largeseeded, short duration, high-yielding kabuli chickpea variety for central India. Int. Chickpea Pigeonpea Newsl., 11: 16-18

Haq, M.A., M. Sadiq, M. Hassan, T.M. Shah, and H. Ali (2002). CM 2000: A new Kabuli chickpea variety. Pakistan J. Seed Tech., 1: 45-49

Haq, M.A., M. Sadiq, and M. Hassan (1999). CM 98 (CM 31-1/85): a very high-yielding, diseaseresistant mutant variety of chickpea. Int. Chickpea Pigeonpea Newsl., 6: 9-10

Hassan, S., and I. Khan (1991). A high yielding chickpea mutant variety NIFA-88 developed through induced mutations. Sarhad J. Agri., 6: 745-750

Iqbal, M.R., M. Bashir, C.A. Rauf, and B.A. Malik (1996). Efficacy of fungicides against soil-borne pathogens of chickpea. Pakistan J. Phytopath., 8: 65-67

Kaloki, P., V. Devasirvatham, and D.Y.K. Tan (2019a). Chickpea abiotic stresses: Combating drought, heat and cold. In abiotic and biotic stress in plants. IntechOpen

Kaloki, P., Q. Luo, R. Trethowan, and D.Y.K. Tan (2019b). Can the development of drought tolerant ideotype sustain Australian chickpea yield?. Int. J. Biometeorol., 63: 393 
Khan, N.H., M. Ahsan, M. Naveed, H.A. Sadaqat and I. Javed (2016). Genetics of drought tolerance at seedling and maturity stages in Zea mays L. Spanish J. Agric. Res. 14(3): 1-11. Doi: 10.5424/sjar/2016143-8505

Malik, M.A., and M. Bashir (1984). Strategies for controlling gram blight. Prog. Farm., 4: 21-23

Maqbool, M.A., M. Aslam and H. Ali (2017). Breeding for improved drought tolerance in chickpea (Cicer arietinum L.). Plant Breed., 136: 300-318

Mehla, I.S., R.S. Waldia, V.P. Singh, V.S. Lather, and S.S. Dahiya (2000). Association of seed mass groups and seed yield in kabuli chickpea. Int. Chickpea Newsl., 7: 7-8

Naveed, M., M. Nadeem, M. Shafiq, C.M. Rafiq and M.A. Zahid (2019). Selection of promising chickpea (Cicer arietinum L.) genotypes using drought tolerance indices. J. Anim. Plant Sci. 29(1): 278-290

Naveed, M., M. Shafiq, C.M. Rafiq, M.K. Naeem and M. Amin (2016a). Grain yield stability of newly evolved desi chickpea strains under rainfed conditions. The J. Anim. Plant Sci. 26: 481-486

Naveed, M., M. Ahsan, H.M. Akram, M. Aslam and N. Ahmed (2016b). Genetic effects conferring heat tolerance in a cross of tolerant $\times$ susceptible maize (Zea mays L.) genotypes. Front. Plant Sci., 7: 29. http://dx.doi.org/10.3389/fpls.2016.00729

Naveed, M., M. Ahsan, H.M. Akram, M. Aslam and N. Ahmed (2016c). Measurement of cell membrane thermos-stability and leaf temperature for heat tolerance in maize (Zea mays L.): Genotypic variability and inheritance pattern. Maydica 61: 1-7

Naveed, M., M. Shafiq, C.M. Rafiq and M.A. Zahid (2015a). Genetic diversity in new chickpea accessions for fusarium wilt resistance, canopy temperature and yield components under drought milieus. Aust. J. Crop Sci. 9: 538-544

Naveed, M., M. Shafiq, C.M. Rafiq, M.A. Zahid and M.S. Saeed (2015b). Planting date effects on the incidence of mungbean yellow mosaic virus (MYMV) and cultivars performance under rainfed environments. Plant Know. J., 4: 7-12

Poehlman, J.M., D.A. Sleper, and J. Rudd (1995). Breeding Field Crops. 378. Ames: Iowa State Uni. Press
Sandhu, J.S., G. Singh, T.S. Bains, Y.R. Sharma, I. Singh, P.S. Sidhu, and S. Singh (2004). PBG 5: A new multiple disease resistant desi chickpea variety for Punjab, India. Int. Chickpea Pigeonpea Newsl., 11: 18-20

Sarwar, N., K.P. Akhtar, T.M. Shah, and B.M. Atta (2012). Evaluation of chickpea advance genotypes against blight and wilt diseases under Field conditions. Int. J. Agric. Biol., 14: 993-996

Shafiq, M., M.S. Akhtar, M. Naveed, A.A. Khan, and N. Muhammad (2011). Punjab-2008, A high yielding and wilt resistant chickpea variety for irrigated and rainfed areas. J. Agric. Res., 49: 19-26

Shah, T.M., B.M. Atta, S.S. Alam, H. Ali, M.A. Haq, and M. Hassan (2010). High yielding kabuli mutant chickpea (Cicer arietinum L.) variety "CM 2008". Pakistan J. Bot., 42: 3533-3545

Shah, T.M., I.M. Javed, M.A. Haq, S.S. Alam, and B.M. Atta (2009). Screening of chickpea (Cicer arietinum) induced mutants against Fusarium wilt. Pakistan J. Bot., 41: 1945-1955

Shah, T.M., M. Hassan, M.A. Haq, B.M. Atta, S.S. Alam, and H. Ali (2005). Evaluation of Cicer Species for resistance to Ascochyta Blight. Pakistan J. Bot., 37: 431-438

Singh, K.B. (1987). Chickpea breeding. In: Saxena, M.C., and K.B. Singh (eds) The Chickpea. CAB Int., Wallingford (UK). $127 \mathrm{p}$

Singh, P.B., S. Ratul, V.S. Chauhan, and K.A. Dilip (2006). Molecular characterization of Fusarium oxysporum f.sp. ciceri causing wilt of chickpea. Afri. J. Biot., 5: 497-502

Waldia, R.S., V.P. Singh, D.R. Sood, P.K. Sardana, and I.S. Mehla (1996). Association and variation among cooking quality traits in kabuli chickpea (Cicer arietinum L.). J. Food Sci. Tech., 33: 397-402

Yadav, S.S., A.K. Verma, A.H. Rizvi, D. Singh, J. Kumar, and M. Andrews (2010). Impact of genotype $\times$ environment interactions on the relative performance of diverse groups of chickpea (Cicer arietinum L.) cultivars. Arch. Agro. Soil Sci., 56: 49-64 